\title{
Las denominaciones del cáñamo: un problema terminológico y lexicográfico*
}

\author{
José Antonio Díaz Rojo \\ Universitat de València-CSIC
}

\section{EL CÁÑAMO Y SUS DENOMINACIONES}

El cáñamo ${ }^{1}$ (llamado científicamente Cannabis sativa, según la denominación que en 1753 le otorgó el botánico sueco C. Linneo) es una planta herbácea conocida desde hace 3000 años, extendida por todo el mundo y con una gran importancia económica, agrícola, industrial y médica, además de por las repercusiones de su uso como droga ${ }^{2}$. De entre sus muchas aplicaciones, las más conocidas son la obtención de la marihuana y de la fibra textil para la elaboración de ropa, papel y otros productos industriales y alimentarios. La existencia de varias subespecies y los diversos avatares históricos han originado una notable diversidad terminológica en torno a la planta. Pero es el hecho de que esta posea diferentes aplicaciones y usos, el motivo de que la terminología del cáñamo se caracterice por un cierto desorden lingüístico, que puede crear confusión semántica y ser incluso objeto de manipulación. Las apli-

* Quisiera expresar mi agradecimiento a Margarita Cantarero, Titulada Superior Especializada del Instituto de Lengua Española (CSIC, Madrid), a Alfonso de la Figuera, presidente de la Sociedad de Estudios del Cáñamo de Aragón (SECA, Zaragoza), a Gaspar Fraga, director de la revista Cáñamo, y a Fernando Lara, profesor del Colegio de México, por sus oportunas aclaraciones a mis preguntas.

1 V. Herer y Figuera (1999) y Escohotado (1997).

2 El Plan Nacional para las Drogas (España) ha lanzado una campaña de publicidad contra el consumo de estupefacientes a mediados de junio del 2003 en que advierte que el "cannabis" potencia los efectos nocivos del tabaco. Por su parte, son muchas las asociaciones y colectivos que abogan por la legalización del cánnabis, negando tales efectos. 
caciones como droga, como recurso terapéutico, como materia prima para la obtención de productos industriales y como alimento merecen designaciones diferentes, si queremos evitar malentendidos, ambigüedades, confusiones y tergiversaciones.

Existen tres subespecies del cáñamo, objeto de numerosas hibridaciones y polihibridaciones: Cannabis sativa sativa, Cannabis sativa indica y Cannabis sativa rudelaris, cada una de ellas con características botánicas, condiciones de cultivo propias y aplicaciones diferentes. Las más importantes son las dos primeras. La planta Cannabis sativa sativa recibe los nombres populares de cáñamo común - por ser la más corriente entre nosotros desde hace siglos-, cáñamo agrario, cáñamo industrial y cáñamo textil-por sus aplicaciones-o simplemente cáñamo. Se plantan los ejemplares con escasa separación, con objeto de que se desarrollen al máximo los tallos, que contienen la fibra utilizada como materia prima. La pulpa y la fibra de esta variante se emplean para la obtención de papel (moneda, de fumar, de periódico, para embalaje, cartón, para impresión láser, etc.), de fibra textil (para cuerdas, velas de barco, redes de pesca, mallas, bolsas, alfombras y ropa, como los primeros pantalones vaqueros Levi's, en los se empleó el tejido obtenido del cáñamo por su dureza y resistencia). De los tallos se fabrican también bioplásticos y materiales de construcción, como conglomerados, paneles, pastillas de freno o discos de embrague. De las semillas, ricas en proteínas y que reciben el nombre de cañamones, se obtienen grasas esenciales para hacer quesos, margarinas, aceites, helados, pastas y pan. Las semillas tienen también aplicaciones terapéuticas, por sus propiedades curativas indicadas contra afecciones del aparato urinario y las inflamaciones. Las modernas teorías sobre alimentación y nutrición atribuyen al cáñamo comestible importantes cualidades para la salud, como el aumento de las defensas del organismo y la prevención de enfermedades cardiovasculares.

La subespecie Cannabis sativa indica es una hierba anual cuyas plantas se cultivan con una separación mayor que la anterior subespecie, para que se desarrollen más sus flores masculinas y femeninas, y sean estas últimas más ricas en sustancias psicotrópicas, especialmente el 1lamado THC (tetrahidrocannabinol), que posee efectos hipnóticos y otras 
propiedades terapéuticas, y que fue aislado en 1964 por el químico R. Mechoulam, de la Universidad de Jerusalén. Según recientes estudios, posee propiedades terapéuticas contra el glaucoma, el dolor crónico, la epilepsia y la esclerosis múltiple, además de aliviar las náuseas, vómitos y pérdida de apetito causadas por la quimioterapia y otros tratamientos contra el sida. Históricamente, en la literatura médica se le atribuían propiedades indicadas contra transtornos de origen nervioso, genitourinario, respiratorio, cutáneo y gastrointestinal. Popularmente recibe los nombres de cánnabis - con las variantes cánabis, cannabis, canabis, tomando la denominación científica más o menos adaptada-, así como cánamo índico, cánamo indiano o cáñamo indio -por su origen geográfico- y cáñamo medicinal-psicoactivo y cáñamo para fines lúdicos o recreativos -por sus aplicaciones como droga y como recurso terapéutico-; al igual que la anterior subespecie dedicada a aplicaciones industriales, en ocasiones la planta empleada como estupefaciente se llama simplemente cáñamo. De ella se obtienen la marihuana y el hachis, términos con diversos sinónimos y variantes ortográficas, como veremos. La marihuana es el producto seco y picado obtenido de las sumidades floridas femeninas - una vez extraída de ellas la resina-, de la hoja, los frutos, los brotes y los tallos blandos, y que posee entre un 1 y un $3 \%$ de THC. El hachís es la resina seca, prensada y comprimida en forma en bloque, tableta, pastilla o caramelo, de color negro, marrón o verdoso, y que contiene hasta un $20 \%$ de THC, si bien hoy se presenta a menudo adulterada con estiércol, piensos compuestos y otras sustancias tóxicas. El cáñamo común solo posee un $0,3 \%$ de THC, de ahí su nulo efecto psicotrópico.

Así pues, la palabra cáñamo se emplea para designar genéricamente a la planta, a cada una de sus variedades, a la fibra textil, y a todas las aplicaciones, ya sean industriales o como droga, dando origen a una polisemia que se puede prestar a equívocos semánticos, como veremos.

\section{EL TÉRMINO CÁNNABIS Y SUS VARIANTES ORTOGRÁFICAS}

Tradicionalmente, el cáñamo empleado como droga recibía en español el nombre de cáñamo índico, cáñamo indiano o cáñamo indio, y en 
ocasiones simplemente cáñamo, como hemos señalado. Sin embargo, durante las últimas décadas, se ha introducido en nuestra lengua el término cánnabis, tomado, a través del inglés, de la denominación científica latina, y que ha ido desplazando a las anteriores palabras. A título de ejemplo, podemos señalar que en el diario El Mundo para designar al cáñamo psicoactivo se emplea el término cánnabis o cannabis (casi nunca canabis, con reducción de $n n$ ) más del triple de veces que cáñamo-nunca cáñamo índico-, mientras que se suele reservar cáñamo para referirse al cáñamo industrial. En la base de datos $C R E A^{4}$, el $80 \%$ de apariciones de cáñamo designan al cáñamo común utilizado como producto textil para fabricar ropa, alpargatas, cuerdas y lienzos. Para referirse al cáñamo psicotrópico, al contrario que en El Mundo, aparecen algunos textos en que se emplea cáñamo índico, indiano o indio.

La palabra cánnabis no solo se emplea para designar a la planta, sino también metonímicamente a la droga obtenida de la misma en sus distintas formas de presentación, como picadura para fumar (marihuana) o pasta comprimida (hachís). Este término aparece también en los textos con las variantes ortográficas cannabis, sin acento, así como canabis o cánabis, con simplificación de la $n$ doble. Esta reducción consonántica no es necesaria, pues el grupo - $n n$ - es propio del español. La palabra presenta otros dos problemas: la acentuación y el género. El término cánnabis es un latinismo recibido a través del inglés, que está perfectamente integrado en español, no solo desde el punto de vista funcional o de uso, sino también formalmente, ya que se ajusta al sistema fonético, ortográfico y morfológico del español. La doble NN latina pasa a $\tilde{n}$ en español en las voces evolucionadas (ANNUS $>$ año, PINNA $>$ piña), mientras que en los cultismos se suele conservar el grupo, y en pocas ocasiones se simplifica.

Existen cultismos y voces patrimoniales derivadas formadas con los prefijos in- (innato, innecesario, innegable, innoble, innovación, innatural, innominado, innumerable, innombrable), en- (ennoblecer, enne-

3 V. El Mundo [en línea]. Hemeroteca online del Mundo. $<$ http://www.elmundo.es/hemeroteca $>$ [Consulta: 25 mayo 2003].

4 V. Real Academia Española [en línea]. Base de datos CREA $<\mathrm{http}: / /$ www.rae.es $>$ [Consulta: 25 mayo 2003]. 
grecer), con- (connatural, connotación, connubio, connivencia, connovicio, connombrar), sin- (sinnúmero) y circun- (circunnavegación), en las que la $n$ doble no se ha reducido. Son pocos los casos en que la simplificación se ha llevado a cabo, como en inocuidad (< latín INNOCUITAS), conexo ( $<$ latín CONNEXUS) y conexión ( $<$ latín CONNEXIO). Además de las anteriores palabras formadas por prefijación, existen otros términos científicos en que se conserva la $n n$, tales como pinna 'folíolo', pinnado, pinnipedo, perenne, perennigélido, perennifolia, gunnerácea 'familia de plantas', estannífera, linneano, annado 'nacido antes', cannácea 'familia de plantas', etc., además de gentilicios como giennesense (de Jaén) -se admiten también jiennense y jienense- y hannoveriano (de Hannover), y el epónimo annamita 'relativo a Anam'.

En cuanto a la acentuación, el término cánnabis debe llevar tilde en la primera $a$, pues es una palabra esdrújula, ya que procede del latín CANNABIS, y en dicha lengua se pronuncian como esdrújulas las palabras que poseen la segunda sílaba breve. En latín era una palabra de género femenino, de ahí que en los compuestos concuerde con adjetivos de este mismo género, como cannabis sativa 'cultivada', y no *cannabis sativo. Dado que el término ha entrado modernamente en el español general a través del inglés -lengua en la que, como es sabido, los sustantivos carecen de género-, en nuestro idioma ha adquirido género masculino, entre otras razones porque se ha asimilado al género del sinómino cáñamo. Esta voz patrimonial evolucionada procede de la variante latina CANNABUM, que ha dado origen a otras palabras como $c a$ ñamazo, cañamero, cañamiza o cañamón.

\section{LOS TÉRMINOS MARIHUANA Y HACHÍS: SINÓNIMOS Y VARIANTES ORTOGRÁFICAS}

Otro de los problemas que plantea la terminología del cáñamo es la forma de las palabras marihuana y hachis. La primera de ellas presenta tres variantes: marihuana, mariguana y marijuana. La forma más antigua y genuina es mariguana, término de etimología incierta procedente del español de México, que empezaron a extender los revolucionarios 
mexicanos de Pancho Villa a fines del siglo XIX. Marihuana es una hipercorrección que se ha convertido en la variante más difundida; uno de los autores que introdujo esta forma en España fue el escritor noventayochista Ramón del Valle-Inclán, que la empleó junto al término cáñamo índico, el habitual en el español peninsular de la época. Marijuana corresponde a una pronunciación aspirada de la $h$, que con intención festiva empleaban los chicanos a principios del siglo XX.

Esta última fue la variante que se implantó en Estados Unidos a partir de los años 30, a raíz de una estrategia política y comercial del magnate W. R. Hearst y del empresario J. Dupont destinada a terminar con el cultivo de cáñamo industrial (en inglés hemp), que dañaba sus intereses comerciales. Para ello, en vez de esta palabra, emplearon como subterfugio el término desconocido marijuana (cáñamo psicoactivo) en una serie de truculentas noticias de prensa que relataban crímenes supuestamente cometidos bajo los efectos del cánnabis, y que fueron publicadas en la poderosa cadena de periódicos de Hearst. Asimismo, para confundir a los congresistas norteamericanos, que creían que estaban votando contra la planta con aplicaciones psicoactivas supuestamente peligrosa, se utilizó también el término marijuana en la ley aprobada en 1937 que de forma encubierta creaba fuertes impuestos al cáñamo en general (Marijuana Tax Law).

La palabra marihuana posee sinónimos actualmente menos utilizados, como hierba, grifa, kifi o maría. Grifa es un mexicanismo aparecido en el siglo XIX; la palabra grifo se empleaba en el sentido de 'persona mareada por efectos de la droga', y de ahí grifa pasó a designar a la marihuana. Era el término más común en la España de los años 50 y 60 para llamar al cánnabis procedente de Marruecos, cuyo consumo por personas marginales y por legionarios y soldados españoles destacados en África era tolerado por el régimen franquista. Sin embargo, cuando comenzó a ser consumido por la juventud rebelde e inconformista y se convirtió en un símbolo hippie del movimiento contracultural, empezó a ser perseguido por el régimen; a partir de entonces, comenzó a extenderse la palabra marihuana, hasta convertirse en la más habitual en la actualidad. El término hachis (pronunciado/jachís/) presenta variantes ortográficas, como haxis, hachich, haschisch, haschís o hashish, pero 
es la forma hachis la más correcta y difundida.

\section{CONFUSIÓN TERMINOLÓGICA}

El tesaurus de drogas del CINDOC (Centro de Información y Documentación $)^{5}$, contiene el término cannabis, cuya definición engloba al cáñamo común (Cannabis sativa) y al cáñamo índico (Cannabis sativa var. indica). En la entrada cáñamo común, señala que "de sus inflorescencias femeninas se extrae una resina que contiene alcaloides con propiedades estupefacientes e hipnóticas". El cáñamo índico lo define como "variedad del cáñamo común, Cannabis sativa, con mayor concentración de alcaloides que éste". El CINDOC emplea el descriptor cannabis como término genérico para las dos variedades de la planta, e indica equivocadamente que el cáñamo común posee efectos psicoactivos, aunque menores que el cáñamo índico. Además incluye entre los "productos de cannabis utilizados como droga" al hachís, la grifa y la marihuana, olvidando que estos dos últimos términos son sinónimos. En el macrotesauro de la OCDE (Organización para la Cooperación y Desarrollo Económico) ${ }^{6}$, el descriptor cáñamo aparece como término específico de fibras textiles, y tiene como términos relacionados cannabis y cordelería. El descriptor cannabis es un específico de estupefacientes, y a su vez posee los términos específicos hachis y marihuana. La OCDE reserva cannabis para la planta con fines psicoactivos y cáñamo para la planta con aplicaciones textiles e industriales.

Como ejemplo de confusión semántica, podemos señalar una polémica entre una periodista del Diario de Ibiza y una empresa de productos cosméticos y alimentarios, originada por la terminología sobre las distintas variedades de cáñamo. La empresa anuncia el lanzamiento de

5 CINDOC [en línea]. Tesaurus de drogas $<$ http://pci204.cindoc.es/tesaurus/Drogas/html/DRO-C0.HTM> [Consulta: 22 mayo 2003].

6 OECD [en línea]. OCDE Macrothesaurus $<$ http://info.uibk.ac.at/info/oecdmacroth/es> [Consulta: 22 mayo 2003]. 
cerveza y golosinas elaboradas con "las hermosas y aromáticas flores y hojas de las puntas de las variedades de la planta del Cannabis sativa, de bajo contenido de THC, autorizadas y subvencionadas por la Comunidad Europea", según sus propias palabras ${ }^{7}$. La periodista publica un artículo titulado "Las posibilidades del cáñamo" con una entradilla donde se lee: "Cannabis. Una empresa comercializará en bares y tiendas diversos productos, entre ellos golosinas y cerveza, realizados con plantas de cáñamo recolectadas en Alemania". En el texto se afirma que los productos están "elaborados con plantas de cánnabis" y, en otro lugar, con "plantas de cáñamo o marihuana". El artículo recoge también las declaraciones del responsable de la empresa, que aclara que los productos están elaborados con "cáñamo industrial", al que también llama "cáñamo agrario". Por su parte, la autora afirma que "en España también existen cultivos de marihuana agrícola" y, reproduciendo palabras del propietario de la empresa, señala que "las leyes permiten el uso del cáñamo industrial siempre que su meta comercial no sea el empleo como droga de abuso".

Obsérvese que la autora, para referirse a la planta de la que se han extraído los productos comercializados por la empresa, emplea, además del término genérico cáñamo, las palabras cannabis y marihuana, utilizadas habitualmente para la planta destinada a su uso como droga, y de forma claramente confusa emplea también el compuesto marihuana agrícola, mezclando las dos aplicaciones del cáñamo, como estupefaciente y como materia prima para productos industriales. Sin embargo, cuando recoge las declaraciones del propietario, emplea los términos cáñamo agrario y cáñamo industrial. Ante ello, la empresa aclara en su página electrónica que la redactora del Diario de Ibiza "intenta manipular la opinión pública", pues "confunde intencionalmente (ya que se le aclaró la diferencia) el cáñamo industrial, o de fibra, con la marijuana, [...] con alto contenido de THC".

7 Dupetit [en línea]. Dupetit Natural Products $<$ http://info.uibk.ac.at/info/oecd-macroth/es> [Consulta: 25 mayo 2003]. 


\section{EL TRATAMIENTO LEXICOGRÁFICO DE LAS DENOMINACIONES DEL CÁÑAMO}

Los diccionarios generales de la lengua presentan también informaciones poco claras que reflejan la confusa situación de la terminología del cáñamo. En este apartado analizaremos las entradas cáñamo y cánnabis en el DRAE, el Diccionario Vox, el Diccionario del español actual de M. Seco, O. Andrés y G. Ramos (DEA), el Diccionario de uso del español de M. Moliner (DUE) y el Diccionario Clave.

El DRAE incluye el término cáñamo, del que registra seis acepciones: la primera pertenece a la botánica, donde describe la planta como especie; la segunda se refiere al 'filamento textil de la planta'; la tercera define la palabra en su sentido de 'lienzo de cáñamo'; según la cuarta acepción, también significa la 'cosa hecha con cáñamo'; su quinta acepción corresponde a un americanismo referido a ciertas plantas textiles; la sexta define el término como 'bramante de cáñamo' en Chile, Costa Rica y Honduras. Incluye además el compuesto cáñamo índico para designar la variedad empleada como droga. El artículo, pues, recoge varios significados de cáñamo: el sentido general de la palabra para referirse a planta como especie, al filamento textil, al género textil y a los objetos de cáñamo, además del compuesto cáñamo indico, que está cayendo en desuso. Asimismo, incluye cannabis -sin acento y de género masculino- como sinónimo de cáñamo índico. Así pues, registra cáñamo con un sentido general (planta) y con sentidos específicos referidos a las aplicaciones textiles.

El Diccionario Vox es más confuso. Incluye cannabis-igualmente sin acento y género masculino-, que define en su primera acepción como sinónimo de cáñamo, y en su segunda como

Polvo obtenido de las flores, hojas y tallos desecados del cáñamo índico del que derivan varias drogas, como el hachís, la marihuana y la grifa.

No lo define como una planta, sino como un polvo extraído de la variedad índica del cáñamo del que dice se obtiene la marihuana y el hachís, pero también la grifa, por lo que parece que los autores del Vox ignoran que la grifa no es otra cosa que la marihuana. En realidad, como 
ya señalamos, el cánnabis es la planta, la marihuana una picadura que se obtiene de las flores femeninas secas y el hachís una especie de tableta comprimida que se extrae de la resina de dichas flores. Es posible que defina el término como 'polvo' por asociación con otras drogas consumidas en forma de polvo.

Incluye también cáñamo, que describe: a) como la variedad empleada para fines textiles, b) como la fibra textil, y c) como lienzo, pero al indicar su nombre científico recoge la denominación genérica de Cannabis sativa, y no Cannabis sativa sativa, que es la que corresponde a la variedad textil. Incluye también cáñamo índico, que define del siguiente modo:

Variedad de cultivo del cáñamo común, de menor talla y peor calidad, pero con mucha concentración de alcaloide. Tiene propiedades estupefacientes e hipnóticas (Cannabis indica).

El cáñamo índico no es una variedad del cáñamo común, sino que más bien el cáñamo índico y el cáñamo común son dos variedades de la misma planta; en cuanto a su calidad, debería especificarse la aplicación para la cual la calidad es escasa, aunque posiblemente se refiera a su calidad como fibra textil o materia prima industrial. La denominación científica latina exacta es Cannabis sativa indica, como ya hemos señalado.

El DEA recoge cannabis -sin acento, de género femenino y pronunciado /kánabis/, con simplificación consonántica en la fonética, aunque no en la grafía- y lo define como "cáñamo índico usado como droga". De la breve descripción, se deduciría que existen otros tipos de cáñamo índico empleados con otros fines. La correcta redacción exige una coma después de "cáñamo índico", para indicar que "usado como droga" es una frase explicativa y no especificativa. Bajo la entrada cánamo, Seco y colaboradores incluyen dos acepciones: una referida a la planta empleada como fibra textil, y otra a la fibra en sí, destinada a la fabricación de cuerdas y similares. Recoge el compuesto cáñamo índico, indiano o indio, que define como

Planta semejante al cáñamo, pero de menor tamaño, y cuyo alcaloide constituye el hachís o marihuana (Cannabis indica). 
No es una planta "semejante al cáñamo", sino que es una variedad de cáñamo; por otra parte, de la conjunción $o$ que une las palabras hachís y marihuana parece deducirse que se trata de dos términos sinónimos, cuando en realidad son dos drogas diferentes derivadas ambas del cánnabis.

El diccionario Clave registra el término cáñamo con dos acepciones: "planta con fines textiles" y "fibra textil", y no incluye el compuesto cáñamo índico. En la entrada cannabis -palabra masculina, según el diccionario- se hace referencia a la planta como especie ("planta herbácea, de hojas compuestas y flores verdes"), y se añade el siguiente ejemplo: "Una especie de 'cannabis' se utiliza como droga". El uso del término especie para designar a la variedad no es muy científico, aunque podría ser aceptable con el sentido popular de 'tipo, clase'; no obstante, debería haberse evitado el empleo de esta palabra, que en el contexto de la taxonomía botánica puede prestarse a confusión, pues en esta disciplina designa un nivel jerárquico determinado en el sistema clasificatorio de los seres vivos.

El DUE recoge el término cáñamo, que define del siguiente modo:

(Cannabis sativa) Planta cannabácea de cuyos tallos se obtiene una fibra textil llamada de la misma manera, de la que se hacen principalmente cuerdas y telas de arpillera, y cuyas semillas son los cañamones.

La definición corresponde a una de las variedades del cáñamo, el común o textil, aunque la denominación científica es la de la especie. Al igual que el DRAE, recoge otras tres acepciones: "nombre aplicado a otras plantas textiles", "bramante", "cosas hechas de cáñamo". Incluye como subentrada el término cáñamo índico, que denomina científicamente Cannabis indica, y que define como "tipo de cáñamo de escaso valor textil, del que se obtiene el hachís", y añade como sinónimo el término cánnabis -esta vez con acento y de género masculino-. Reserva, pues, la palabra cáñamo para el cáñamo común. 


\begin{tabular}{|c|c|c|c|}
\hline & cáñamo & cáñamo índico & cánnabis \\
\hline$D R A E$ & $\begin{array}{l}\text { 1) planta (especie) } \\
\text { 2) filamento textil } \\
\text { 3) lienzo } \\
\text { 4) cosa hecha con } \\
\text { cáñamo } \\
\text { 5) plantas textiles } \\
\text { 6) bramante }\end{array}$ & $\begin{array}{l}\text { planta (variedad } \\
\text { para droga) }\end{array}$ & $\begin{array}{l}\text { cannabis }(\mathrm{m} .) \\
\text { planta (variedad } \\
\text { para droga) }\end{array}$ \\
\hline$D E A$ & $\begin{array}{l}\text { 1) planta (variedad } \\
\text { textil) } \\
\text { 2) fibra textil }\end{array}$ & $\begin{array}{l}\text { planta (variedad } \\
\text { para droga) }\end{array}$ & $\begin{array}{l}\text { cannabis (f.) / } \\
\text { /kanabis/ } \\
\text { planta (variedad } \\
\text { para droga) }\end{array}$ \\
\hline$D U E$ & $\begin{array}{l}\text { 1) planta (variedad } \\
\text { textil) } \\
\text { 2) plantas textiles } \\
\text { 3) bramante } \\
\text { 4) cosas hechas con } \\
\text { cáñamo }\end{array}$ & $\begin{array}{l}\text { planta (variedad } \\
\text { para droga) }\end{array}$ & $\begin{array}{l}\text { cánnabis }(\mathrm{m} .) \\
\text { planta (variedad } \\
\text { para droga) }\end{array}$ \\
\hline Vox & $\begin{array}{l}\text { 1) planta (variedad } \\
\text { textil) } \\
\text { 2) fibra } \\
\text { 3) lienzo }\end{array}$ & polvo (droga) & $\begin{array}{l}\text { cannabis (m.) } \\
\text { 1) planta (variedad } \\
\text { textil) } \\
\text { 2) fibra } \\
\text { 3) lienzo } \\
\text { 4) planta (variedad } \\
\text { para droga) }\end{array}$ \\
\hline Clave & $\begin{array}{l}\text { 1) planta (variedad } \\
\text { textil) } \\
\text { 2) fibra textil }\end{array}$ & & $\begin{array}{l}\text { cannabis (m.) } \\
\text { planta (especie) }\end{array}$ \\
\hline
\end{tabular}

En resumen, pues, observamos que:

El término cánnabis está recogido en todos los diccionarios, escrito sin acento y con $n$ doble, a excepción del $D U E$, que lo acentúa; todos le asignan el significado de "planta usada como droga". Solo el Vox inclu- 
ye, además de este significado, otros sentidos referidos a la variedad textil; el Clave lo registra con la acepción genérica referida a la planta como especie. En todos los diccionarios se indica que es de género masculino, siguiendo el uso más frecuente, excepto el $D E A$, que lo considera femenino, respetando la etimología latina.

Cáñamo se reserva para la variedad textil, sus derivados y aplicaciones, en todos los diccionarios. El DRAE recoge también el sentido de 'planta', pero referido a toda la especie.

Cáñamo índico aparece en todos los diccionarios a excepción del Clave, para designar a la planta empleada como estupefaciente, a pesar de que es un término que está cayendo en desuso.

No se registran términos como cáñamo industrial, cáñamo agrario, cáñamo textil y cánamo común.

La situación lexicográfica anteriormente descrita es un ejemplo de que, ante una situación de diversidad - o desorden- terminológica, los diccionarios suelen describir dicha situación de forma parcial, cuando no inexacta, confusa o imprecisa. No es infrecuente que para resolver dudas terminológicas, el lector consulte más de un diccionario, buscando una información más veraz y completa; paradójicamente, la consulta de varios diccionarios sumirá al lector en la perplejidad ante la maraña de informaciones contradictorias: por ello, la lexicografía debe esforzarse por describir los usos reales, advirtiendo de los problemas que plantean los términos conflictivos, por medio de notas, glosas y otros recursos. La representación lexicográfica de las unidades terminológicas con problemas normativos (vacilación, alternancia o desviación de la norma) debe orientar al lector acerca de la situación real en que se hallan dichos términos, para que el usuario conozca el "desorden" terminológico que afecta al uso, y a la vez tenga conocimiento de las soluciones más correctas, y utilice así las palabras de forma precisa y clara, aprovechando sus posibilidades expresivas. 


\section{UNA PROPUESTA TERMINOLÓGICA}

Ante esta confusión terminológica, Gaspar Fraga, director de la revista Cánamo, propone establecer la siguiente distinción: emplear “cánnabis en su contexto botánico, terapéutico, medicinal y clásico; cáñamo como concepto industrial y ecologista; y marihuana como concepto lúdico y recreativo"s.

$\mathrm{Al}$ referirnos al cáñamo, debe quedar claro, por tanto, a qué variedad de la planta nos estamos refiriendo: a la subespecie Cannabis sativa sativa, que es el cáñamo con fines industriales (que podemos llamar cáñamo común, cáñamo industrial, cáñamo agrario o cáñamo textil) y alimenticios (cáñamo comestible); o, por el contrario, a la variedad Cannabis sativa indica, que podemos seguir llamando con el nombre tradicional, cáñamo índico, si bien, dado que esta denominación está cayendo en desuso, es también aceptable llamarla cánnabis -con tilde y $n$ doble-, como suele hacerse actualmente. Para referirnos a la droga, emplearemos, además del término genérico, los términos específicos habituales para cada derivado, marihuana y hachís. La palabra cáñamo se reservaría para denominar a la planta en su sentido más genérico, en aquellos contextos en que hablemos de la especie en general, sin especificar tipos ni aplicaciones.

8 [Entrevista realizada a Gaspar Fraga, 1999] [en línea]

$<$ http://www.mind-surf.net/drogas/entrevistagasparfraga.htm $>$ [Consulta: 19 mayo 2003]. 
BIBLIOGRAFÍA

Maldonado, C. (dir.) (1999): Diccionario de uso del español actual Clave, Madrid, SM [Clave].

Escohotado, Antonio (1997): La cuestión del cáñamo, Barcelona, Anagrama.

HeREK, Jack y Alfonso de la FigUERA (1999): El emperador está desnudo: el cáñamo y la conspiración de la marihuana, Castellar de la Frontera, Castellarte.

Vox (1998): Diccionario ideológico de la lengua española VOX, Barcelona, Biblograf.

Moliner, María (1999): Diccionario de uso del español, Madrid, Gredos $[D U E]$.

Real Academia Española (2001): Diccionario de la lengua española, Madrid, Espasa-Calpe [DRAE].

SeCo, Manuel, Olimpia de Andrés y Gabino Ramos (1999): Diccionario del español actual, Madrid, Aguilar [DEA]. 